\title{
Health Beliefs as Predictors of Breast Self-Examination Behavior
}

\author{
Fatemeh Mousavi ${ }^{1}$, Parisa Shojaei ${ }^{1^{*}}$ and Sam Homasan ${ }^{2}$ \\ ${ }^{1}$ Department of Community \& Preventive Medicine, Social Determinants of Health Research Center, \\ Tehran Medical Science Branch, Islamic Azad University, Tehran, Iran \\ ${ }^{2}$ Medical student, Tehran Medical Science Branch, Islamic Azad University, Tehran, Iran
}

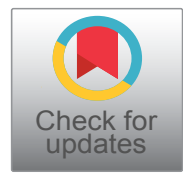

*Corresponding author: Parisa Shojaei, Department of Community \& Preventive Medicine, Social Determinants of Health Research Center, Tehran Medical Science Branch, Islamic Azad University, Tehran, Iran, Tel: 00989192965126

\begin{abstract}
Background: The purpose of the present study was to investigate the frequency of getting such health screenings as breast self-examination among a group of women and to identify the role of health beliefs in predicting breast self-examination (BSE).

Methods: The data were collected from a convenience sample of 225 women covered of the clinics in northwest of Tehran. The participants completed the demographic questions and Champion Health Beliefs Scale (CHBS) designed to measure patients' perception on breast self-examination of breast cancer screening. Also answered The Breast Cancer Knowledge Test (BCKT) that was applied to measure participants' knowledge.

Results: The results indicated that $52 \%$ of women before did Breast Self-Examination and had poor knowledge on breast cancer. Most disagree about questions of Champion Health Beliefs Scale was with phrase of "I do not check because the leave the condition on God" and most agree with "Early detection leads less surgical intervention and best healing". Logistic regression showed that educational status, breastfeeding and the perceived barriers significantly predicted BSE ( $P$ value $<0.05)$.

Conclusion: The study revealed that the HBM constructs are able to predict BSE behavior. Among these constructs, perceived barriers was the most important predictor of the behavior. Interventions based on the constructs of perceived barriers and educational interventions are recommended for increasing women's regular screening for breast cancer.
\end{abstract}

\section{Keywords}

Breast self-examination, Breast cancer, Women, Health belief model

\section{Introduction}

Cancer is life-threatening condition can affect com- munity health. Commonly the most cancers cause death are: lung cancer, gastric cancer, colon cancer and breast cancer [1]. Breast cancer is a common cancer in both developing and developed countries [2]. This cancer is the first common cancer in woman at the age of 40-60 years and the second common among them at 30-40 in the world [3]. It is estimated that one in 20 women with breast cancer is diagnosed throughout their lives [4]. The prevalence of breast cancer in Iranian women is 25 in among 100000 [5] and is doubled in the past 10 years. The age of getting breast cancer is about 10 years earlier in Iran in comparison with developed countries [3] mortality of breast cancer mostly occur in developing countries and low economic areas [6] cause breast cancer is being diagnosed in high stages due to absence of diagnostic and treatment equipment like mammography and radio therapy [7]. The most disposing factors are female gender, age, family history. First degree family members of the patient including mother sister and daughter are in danger and family history is positive in $5-10 \%$ of patients [8]. According to studies in the middle east seems that an elevation in prevalence of this cancer could because of: changing life style, eating habits, low activity, marriage in old ages, and delayed first pregnancy in second and third decade of life and low breast feeding time [9]. In Cancer Prevention and Control (CDC) 2020 health goal women's awareness to this cancer and screening of it is considered, diagnostic and screening programs [3]. The Global Breast Cancer Screening Program, introduced in 2012, recommends the following screening for breast cancer: include 1-mamography in women over the age of 40 each year, 
2-physical examination at the age of 20-40 each 3 years and yearly over the age of 40, 3-self exam over the age of 20 monthly [5]. Self-exam help women to know the texture of their breast and be aware of any possible changes [4]. Breast self-examination (BSE) is one of the accepted methods for increasing breast health awareness. This is a cheap and non-invasive method without waste of time [10]. The American Cancer Society recommends that BSE be initially diagnosed at age 20 when it comes to low-cost screening and easy self-test breast testing. 95\% of breast cancers in America is detected by the BSE and on the other hand $75 \%$ those whom their mass is detected bay themselves have a survival of 5 years but this number in other women is $57 \%$, BSE in seventh to tenth day of period is a key method to diagnose the cancer [11]. BSE has no side effects in women [2]. Studies have shown that the low level of BSE among low-educated Iranian women is associated with a lack of information on BSE and a positive family history [10]. Therefore, the participation of women in the diagnostic and screening program is very important. The level of women's participation is influenced by various factors such as social factors, lack of examining education, cultural barriers and different sensitivities, economic problems, lack of examination training, lack of awareness, mental disorders, fear of breast cancer diagnosis, and negative attitude toward findings [3]. The Health Belief Model (HBM) is one of the most important behavior change models and has been widely used to examine beliefs related to preventive health behaviors such as $\mathrm{BSE}$, clinical breast examination (CBE), and mammography [12]. The HBM was developed by Becker [13] and modified by Rosenstock [14], and it may be beneficial inexploring the factors influencing women's breast cancer screening behaviors [5]. The HBM includes six constructs: 1) Perceived susceptibility shows a person's perception towards the risk of a specific disease; 2) Perceived seriousness determines a person's feeling towards the side effects of a disease; 3 ) Perceived benefits indicates a person's perception towards the positive health consequences of performing a specific health behavior; 4) Perceived barriers highlight a person's perception of the costs or barriers to a given health behavior; 5) Health motivation refers to an individual's beliefs and behaviors towards a general health concern; and 6) Self-efficacy refers to a person's confidence in his/her ability to adopt a given health behavior. According to this model, when a woman feels that she is vulnerable to a specific disease or when she perceives that the disease has reached a dangerous state, she will be more likely to perform breast cancer-related screening behaviors [15]. Among breast cancer screening tests, the BSE is still considered a simple, noninvasive, inexpensive, affordable and accessible method for women who are younger and at a high risk to detect early changes in their breasts [16]. This study applied the HBM as a theoretical basis to explore variables affecting BSE behavior among women covered of the private clinic of Medical Science University, Tehran, Iran.

\section{Methods}

\section{Design \& Setting}

A descriptive cross-sectional design was utilized to study the perception of female about breast cancer and the relationship between variables (demographic characteristics and their perception regarding breast cancer). The study was conducted in 2018. 225 Iranian women with simple random method selected from women who had medical records in this center and asked them to set dates One week's time for participant in the study and individual that referred to the private educational, research and therapeutic center in northwest of Tehran. The center is the only private center affiliated with one of the medical universities in the region studied and have large covered population in its area. Written informed consent was obtained from all the women who participated in the study.

\section{Sample \& Sampling technique}

The sample size was calculated to measure an expected satisfactory perception rate of $50 \%$ or higher, with absolute precision $5 \%$ ( $10 \%$ of the prevalence). Inclusion criteria are women over 18 age and absence of breast malignant or benign lesion and exclusion criteria are pregnancy and breast-feeding.

\section{Data collection tools}

To collect the study data, researchers developed a 20 min self-report questionnaire using previous scientific literature and scales. This instrument included the following three subscales:

1. Demographic characteristics: age, number of children, marital status, occupation, educational status, past medical history, kind of problem, history of breastfeeding, and family history of breast cancer.

2. The Breast Cancer Knowledge Test (BCKT) developed by Mc Cane, et al. was applied to measure participants' knowledge [17]. The instrument was submitted to four experts in the field of oncology to establish content validity. Reliability testing was conducted on a random sample of 182 women. Internal consistency reliability for the post-tested general knowledge subscale was 0.60, and for the curability, subscale was 0.62 . The overall alpha coefficient was 0.71. In combination with the BCKT, these subscales can be used to describe a woman's knowledge of breast cancer [18]. The BCKT is a 19 item instrument that measures subjects' knowledge of breast cancer detection and screening practices. Each correct response was scored as one and each false and "do not know" response was scored as zero. The sum of the correct answer is sum score. The reliability and validity of the Persian version of this instrument in Iran 
is conducted by Didarloo, et al. First, the instrument was translated into Farsi, and then the questionnaire was translated by two English-English professors and compared to the original version, which had the same concepts and finally the final questionnaire was developed. To determine the validity of the final questionnaire, a qualitative method (content validity) was used for this tool, which was sent through the system of faculty members as a panel of experts to 10 emails and asked them to examine the questionnaire in terms of clarity, relevance, and necessity of the review. After receiving the feedback and suggestions from the experts, the necessary corrections were made in the questionnaire and finally the instrument was approved for validity. For reliability, was used test retest. The correlation coefficient was 0.81 and the reliability was confirmed [19].

3. Part 3 perception of women about BC and BSE. It was assessed by a scale that is the modified HBM for BC instrument and composed of 26 questions [7] which was measured through use the health belief model (HBM), the statements of the HBM variables is (perceived susceptibility, perceived severity, perceived benefits and perceived barriers). The current scale was developed based on the work of many researchers [20]. On the other hand, the modified HBM for BC instrument included 26 items on four constructions, perceived susceptibility - "SUS" (3 items), perceived severity - "SER" (7 items), perceived benefits - "BEN" (5 items), perceived barriers "BAR" (11 items). Participants rated these statements using a five-point Likert scale (strongly agree, agree, undecided, disagree, strongly disagree) each statement was scored from 1 to 5 where 5 indicates strong or higher perception and 1 indicates weak or lower perceptions. The Reliability, internal consistency and content validity was done by Al-Harbim, et al. [7]. Poorhaji, et al. conducted the reliability of Persian version of this model in Iran that was calculated using Cronbach's alpha- 8 coefficient of 0.5 . Content validity method was used for validity of the questionnaire. Questions and corrections were made by 25 professors in the field of health education and gynecologists and oncology experts from the medical universities of the country [21].

\section{Statistical analysis}

To analyze the study data, the researchers applied descriptive and inferential statistical methods. $\chi^{2}, \mathrm{t}$ test, ANOVA and correlate was conducted to assess the relationship between two categorical variables. In addition, a logistic regression was applied to determine the factors affecting behavior using SPSS software version 22.0. In this study, a P value less than 0.05 was considered significant in all the analyses.

\section{Results}

In this study, with a sample size of 225 , the average
Table 1: Distribution of the women' socio-demographic Characteristics $(n=225)$.

\begin{tabular}{|c|c|c|}
\hline Characteristics & Number & Percent \\
\hline Education & $N=225$ & \\
\hline Under diploma & 8 & 3.6 \\
\hline Diploma & 67 & 29.8 \\
\hline Bachelor & 77 & 34.2 \\
\hline Master & 73 & 32.4 \\
\hline Occupation & $N=222$ & \\
\hline Employee & 72 & 32 \\
\hline Self-employer & 18 & 8 \\
\hline Housewife & 61 & 27.1 \\
\hline Unemployed & 64 & 28.4 \\
\hline Retired & 7 & 3.1 \\
\hline Marital status & $N=225$ & \\
\hline Single & 98 & 43.6 \\
\hline Married & 118 & 52.4 \\
\hline Divorced & 7 & 3.1 \\
\hline Widow & 2 & 9 \\
\hline $\begin{array}{l}\text { Have you ever had } \\
\text { breastfeeding? }\end{array}$ & $N=224$ & \\
\hline No & 129 & 57.3 \\
\hline Yes & 95 & 42.2 \\
\hline $\begin{array}{l}\text { Is there a history of } \\
\text { breast cancer in your } \\
\text { family? }\end{array}$ & $N=225$ & \\
\hline I don't know and No & 154 & 68.4 \\
\hline Yes & 71 & 31.6 \\
\hline $\begin{array}{l}\text { Have you ever seen a } \\
\text { doctor about your breast } \\
\text { discomfort? }\end{array}$ & $N=225$ & \\
\hline No & 168 & 74.7 \\
\hline Yes & 57 & 25.3 \\
\hline What is your problem? & $N=225$ & \\
\hline No problem & 168 & 74.7 \\
\hline Pain & 16 & 7.1 \\
\hline Benign & 8 & 3.6 \\
\hline Cyst & 25 & 11.1 \\
\hline Fibroma & 2 & 0.9 \\
\hline Discharge & 1 & 0.4 \\
\hline Others & 5 & 2.2 \\
\hline
\end{tabular}

age of participants was $35 / 16+/-12 / 88$ and the average number of children was $0.87+/-1.25$. Demographic information shown in Table 1. General average of women awareness was $7.28+/-3.90$ out of 19 . In questions of health believes most disagree question was "I do not check because leave the condition on god" and most agree one is "early detection leads less surgical intervention and the best healing". $52 \%$ of them had done BSE (Table 2).

The ANOVA showed that a statistically significant difference between age, sensitivity obstacles and gains but no statistically significant difference between number of children and accepted sensitivity. The test reveal that between occupation marital status and educational status with sensitivity obstacles is no significant relation 
Table 2: Participant's perception level about breast cancer.

\begin{tabular}{|c|c|c|c|}
\hline Items & Responses & (n) & $\%$ \\
\hline \multicolumn{4}{|l|}{ Perceived susceptibility } \\
\hline \multirow[t]{6}{*}{ Because I am a woman susceptible to breast cancer } & & $N=225$ & \\
\hline & Strongly disagree & 16 & 7.1 \\
\hline & Disagree & 51 & 22.7 \\
\hline & Undecided & 25 & 11.1 \\
\hline & Agree & 87 & 38.7 \\
\hline & Strongly agree & 46 & 20.4 \\
\hline \multirow[t]{5}{*}{$\begin{array}{l}\text { Compare my health to other, I feel more injury to breast cancer than } \\
\text { others }\end{array}$} & Strongly disagree & $\begin{array}{l}N=225 \\
29\end{array}$ & 12.9 \\
\hline & Disagree & 84 & 37.3 \\
\hline & Undecided & 54 & 24 \\
\hline & Agree & 37 & 16.4 \\
\hline & Strongly agree & 21 & 9.3 \\
\hline \multirow[t]{6}{*}{ Increasing the possibility of breast cancer, with advance the age } & & $N=225$ & \\
\hline & Strongly disagree & 7 & 3.1 \\
\hline & Disagree & 36 & 16 \\
\hline & Undecided & 64 & 28.4 \\
\hline & Agree & 80 & 35.6 \\
\hline & Strongly agree & 38 & 16.9 \\
\hline \multicolumn{4}{|l|}{ Perceived severity } \\
\hline \multirow[t]{6}{*}{ I feel of fear from injury of breast cancer } & & $N=225$ & \\
\hline & Strongly disagree & 10 & 4.4 \\
\hline & Disagree & 43 & 19.1 \\
\hline & Undecided & 35 & 15.6 \\
\hline & Agree & 95 & 42.2 \\
\hline & Strongly agree & 42 & 18.7 \\
\hline \multirow[t]{6}{*}{ Breast cancer dangerous to my health } & & $N=225$ & \\
\hline & Strongly disagree & 7 & 3.1 \\
\hline & Disagree & 42 & 18.7 \\
\hline & Undecided & 20 & 8.9 \\
\hline & Agree & 98 & 43.6 \\
\hline & Strongly agree & 58 & 25.8 \\
\hline \multirow[t]{6}{*}{ I am permanently concerned of breast cancer } & & $N=225$ & \\
\hline & Strongly disagree & 21 & 9.3 \\
\hline & Disagree & 89 & 39.6 \\
\hline & Undecided & 45 & 20 \\
\hline & Agree & 40 & 17.8 \\
\hline & Strongly agree & 30 & 13.3 \\
\hline \multirow{6}{*}{$\begin{array}{l}\text { Breast cancer possible that threatens your future educational and } \\
\text { practical }\end{array}$} & & $N=225$ & \\
\hline & Strongly disagree & 25 & 11.1 \\
\hline & Disagree & 64 & 28.4 \\
\hline & Undecided & 41 & 18.2 \\
\hline & Agree & 56 & 24.9 \\
\hline & Strongly agree & 39 & 17.3 \\
\hline \multirow[t]{6}{*}{ Breast cancer adversely affects the physical conditions of the patient } & & $N=225$ & \\
\hline & Strongly disagree & 7 & 3.1 \\
\hline & Disagree & 34 & 15.1 \\
\hline & Undecided & 36 & 16 \\
\hline & Agree & 99 & 44 \\
\hline & Strongly agree & 49 & 21.8 \\
\hline \multirow[t]{6}{*}{ Breast cancer threatens the marital and family relations } & & $N=225$ & \\
\hline & Strongly disagree & 17 & 7.6 \\
\hline & Disagree & 37 & 16.4 \\
\hline & Undecided & 37 & 16.4 \\
\hline & Agree & 92 & 40.9 \\
\hline & Strongly agree & 42 & 18.7 \\
\hline
\end{tabular}


Breast cancer as possible causes of death in the absence of early treatment

\begin{tabular}{|c|c|c|c|}
\hline & & & \\
\hline & Disagree & 26 & 11.6 \\
\hline & Undecided & 39 & 17.3 \\
\hline & Agree & 82 & 36.4 \\
\hline & Strongly agree & 65 & 28.9 \\
\hline \multicolumn{4}{|l|}{ Perceived benefit } \\
\hline \multirow[t]{6}{*}{ Breast self-exam procedure is useful to those who are in same age } & & $N=225$ & \\
\hline & Strongly disagree & 7 & 3.1 \\
\hline & Disagree & 14 & 6.2 \\
\hline & Undecided & 50 & 22.2 \\
\hline & Agree & 85 & 37.8 \\
\hline & Strongly agree & 69 & 30.7 \\
\hline \multirow[t]{6}{*}{ Breast self-exam helps early detection of breast cancer } & & $N=225$ & \\
\hline & Strongly disagree & 9 & 4 \\
\hline & Disagree & 6 & 2.7 \\
\hline & Undecided & 23 & 10.2 \\
\hline & Agree & 93 & 41.3 \\
\hline & Strongly agree & 94 & 41.8 \\
\hline \multirow[t]{6}{*}{ Early detection leads less surgical intervention and best healing } & & $N=225$ & \\
\hline & Strongly disagree & 12 & 5.3 \\
\hline & Disagree & 11 & 4.9 \\
\hline & Undecided & 24 & 10.7 \\
\hline & Agree & 77 & 34.2 \\
\hline & Strongly agree & 101 & 44.9 \\
\hline \multirow[t]{6}{*}{ Breast self-exam is an effective method for detecting cancer } & & $N=225$ & \\
\hline & Strongly disagree & 12 & 5.3 \\
\hline & Disagree & 17 & 7.6 \\
\hline & Undecided & 46 & 20.4 \\
\hline & Agree & 79 & 35.1 \\
\hline & Strongly agree & 71 & 31.6 \\
\hline \multirow{6}{*}{$\begin{array}{l}\text { Procedural breast self-exam regularly it reduces the fear of breast } \\
\text { cancer }\end{array}$} & & $N=225$ & \\
\hline & Strongly disagree & 12 & 53 \\
\hline & Disagree & 26 & 11.6 \\
\hline & Undecided & 56 & 24.9 \\
\hline & Agree & 74 & 32.9 \\
\hline & Strongly agree & 57 & 25.3 \\
\hline \multicolumn{4}{|l|}{ Perceived barriers } \\
\hline \multirow[t]{6}{*}{ I don't find time to perform breast self-exam } & & $N=225$ & \\
\hline & Strongly disagree & 37 & 16.4 \\
\hline & Disagree & 81 & 36 \\
\hline & Undecided & 40 & 17.8 \\
\hline & Agree & 50 & 22.2 \\
\hline & Strongly agree & 17 & 7.6 \\
\hline \multirow[t]{6}{*}{ I don't see the importance to conduct breast self-exam } & & $N=225$ & \\
\hline & Strongly disagree & 56 & 24.9 \\
\hline & Disagree & 95 & 42.2 \\
\hline & Undecided & 32 & 14.2 \\
\hline & Agree & 29 & 12.9 \\
\hline & Strongly agree & 13 & 5.8 \\
\hline \multirow[t]{6}{*}{ I don't know the correct way to conduct breast self-exam } & & $N=225$ & \\
\hline & Strongly disagree & 37 & 16.4 \\
\hline & Disagree & 67 & 29.8 \\
\hline & Undecided & 22 & 9.8 \\
\hline & Agree & 70 & 31.1 \\
\hline & Strongly agree & 29 & 12.5 \\
\hline
\end{tabular}




\begin{tabular}{|c|c|c|c|}
\hline \multirow[t]{6}{*}{ Breast self-exam increases my anxiety and fear } & & $N=225$ & \\
\hline & Strongly disagree & 50 & 22.2 \\
\hline & Disagree & 75 & 33.3 \\
\hline & Undecided & 43 & 19.1 \\
\hline & Agree & 37 & 16.1 \\
\hline & Strongly agree & 20 & 8.9 \\
\hline \multirow[t]{6}{*}{ Not conducted breast self-exam because of fear of cancer is detected } & & $N=225$ & \\
\hline & Strongly disagree & 59 & 26.2 \\
\hline & Disagree & 81 & 36 \\
\hline & Undecided & 28 & 12.4 \\
\hline & Agree & 38 & 16.9 \\
\hline & Strongly agree & 19 & 8.4 \\
\hline \multirow[t]{6}{*}{ Do not check because my age is an exhibition of cancer } & & $N=225$ & \\
\hline & Strongly disagree & 76 & 33.8 \\
\hline & Disagree & 89 & 39.6 \\
\hline & Undecided & 33 & 14.7 \\
\hline & Agree & 16 & 7.1 \\
\hline & Strongly agree & 11 & 4.9 \\
\hline \multirow[t]{6}{*}{ I do not check because no one from the family has had cancer } & & $N=225$ & \\
\hline & Strongly disagree & 73 & 32.4 \\
\hline & Disagree & 87 & 38.7 \\
\hline & Undecided & 23 & 10.2 \\
\hline & Agree & 30 & 13.3 \\
\hline & Strongly agree & 12 & 5.3 \\
\hline \multirow[t]{6}{*}{ I do not check for that defect } & & $N=225$ & \\
\hline & Strongly disagree & 61 & 27.1 \\
\hline & Disagree & 76 & 33.8 \\
\hline & Undecided & 32 & 14.2 \\
\hline & Agree & 35 & 15.6 \\
\hline & Strongly agree & 21 & 9.3 \\
\hline \multirow[t]{6}{*}{ I do not check because it is discomfort } & & $N=225$ & \\
\hline & Strongly disagree & 68 & 30.2 \\
\hline & Disagree & 83 & 36.9 \\
\hline & Undecided & 27 & 12 \\
\hline & Agree & 30 & 13.3 \\
\hline & Strongly agree & 17 & 7.6 \\
\hline \multirow[t]{6}{*}{ I do not check because of laziness } & & $N=225$ & \\
\hline & Strongly disagree & 56 & 24.9 \\
\hline & Disagree & 76 & 33.8 \\
\hline & Undecided & 22 & 9.8 \\
\hline & Agree & 52 & 23.1 \\
\hline & Strongly agree & 19 & 8.4 \\
\hline \multirow[t]{6}{*}{ I do not check because the leave the condition on god } & & $N=225$ & \\
\hline & Strongly disagree & 95 & 42.2 \\
\hline & Disagree & 83 & 36.9 \\
\hline & Undecided & 20 & 8.9 \\
\hline & Agree & 17 & 7.6 \\
\hline & Strongly agree & 10 & 4.4 \\
\hline
\end{tabular}

breast feeding with those the same but positive family history with sensitivity and severity related. There was no significant relations between history of breast problems and visiting a doctor with age, sensitivity and benefits. Correlation test show that there was significant correlation between age and general awareness but also no significant correlation between number of children and general. Statistically significant difference was found between education and general awareness according to ANOVA test. There was no significant difference between occupation and general awareness as well as between marital status and general awareness according to ANOVA test. In questions of awareness, the most well-known question is relation between breast cancers, existence of small tender glands in breast before menstruation with 194 persons replied correctly, 
Table 3: Logistic regression analysis predicting BSE practice

\begin{tabular}{|l|l|l|l|l|l|l|l|}
\hline & B & S.E. & Wald & Sig. & Odds Ratio & \multicolumn{2}{l|}{ 95\% C.I. for EXP (B) } \\
\hline Age & & & & & & Lower & Upper \\
\hline Number of children & -0.011 & 0.029 & 0.144 & 0.705 & 0.989 & 0.935 & 1.047 \\
\hline Job & 0.104 & 0.316 & 0.109 & 0.741 & 1.110 & 0.598 & 2.060 \\
\hline Educational status & -1.135 & 1.428 & 0.631 & 0.427 & 0.321 & 0.020 & 5.283 \\
\hline Marital status & -1.244 & 0.529 & 5.535 & 0.019 & 0.288 & 0.102 & 0.813 \\
\hline Breastfeeding & 4.334 & 2.201 & 3.880 & 0.049 & 76.269 & 1.022 & 5694.012 \\
\hline History of cancer in family & -1.492 & 0.682 & 4.784 & 0.029 & 0.225 & 0.059 & 0.856 \\
\hline Past medical history & -0.492 & 0.426 & 1.336 & 0.248 & 0.612 & 0.266 & 1.408 \\
\hline Examined by a physician & 0.329 & 0.815 & 0.163 & 0.686 & 1.390 & 0.281 & 6.872 \\
\hline Kind of problem & 0.309 & 1.336 & 0.053 & 0.817 & 1.362 & 0.099 & 18.697 \\
\hline Perceived severity & -1.030 & 2.008 & 0.263 & 1 & 0.608 & 0.357 & 0.007 \\
\hline Perceived susceptibility & -0.011 & 0.026 & 0.181 & 0.671 & 0.989 & 0.940 & 1.041 \\
\hline Perceived benefits & 0.030 & 0.053 & 0.319 & 0.572 & 1.030 & 0.929 & 1.142 \\
\hline Perceived barriers & 0.000 & 0.039 & 0.000 & 0.990 & 1.000 & 0.927 & 1.079 \\
\hline Knowledge & -0.105 & 0.024 & 19.245 & 0.000 & 0.900 & 0.859 & 0.943 \\
\hline B: Beta; S.E: Standary & 0.085 & 0.051 & 2.799 & 0.094 & 1.089 & 0.986 & 1.203 \\
\hline
\end{tabular}

B: Beta; S.E: Standard Error; p: p value; C.I.: Confidence Interval.

less awareness was about relation between early menstruation, and cancer which was replied incorrectly. To evaluate the predictive value of the variables of BSE, a logistic regression was performed with BSE as dependent variable, and age, number of children, job, marital status, educational status, Past medical history, Examined by a physician, kind of problem, family history of cancer, knowledge, perceived susceptibility, perceived benefits, and perceived barrier as predictor variables. As shown in Table 3, only four of the independent variables including marital status, Educational status, Breastfeeding and the perceived barriers made a significant contribution to the model. The analysis indicated that women who saw fewer barriers to get a BSE and whose had high educational status, had breastfeeding and married, had a higher probability to get a BSE. Table 3 provides coefficients, the Wald statistic and probability values for each of the predictor variables.

\section{Discussion}

This study focused on defining the health beliefs of Iranian women regarding BSE and the influencing factors. Influencing factors. In the present study, women had poor knowledge on breast cancer. A lack of knowledge about women's health is a factor that can impede preventive practices against different diseases. It means that knowledge plays a principal role in adopting and conducting health-promoting behaviors. This was compatible with the didarlu and colleagues $[4,22]$. The results of a study in Spain show that only $9.7 \%$ of them had enough knowledge of screening programs [23]. In this study is a direct relation between general awareness with perceived severity but between general awareness and other factors was no relations $[P<0.05]$. It is natural that the higher the level of awareness, the individuals will have more information and understanding of the factors associated with breast cancer and more often they are doing breast self-examination. In the study in India between general awareness and per- ceived severity sensitivity obstacles and benefits was no relations [24]. In the study which was conducted in Saudi Arabia in 2015 general awareness and obstacles and benefits was related [22]. In other study in Jordan on 100 female indicated awareness is directly related to other fields of health [25]. The overall knowledge score was not significant predictor of BSE performance. This is not consistent with previous studies $[26,27]$. Perhaps in our investigated community, factors that are more important than awareness, such as culture and other important barriers, are predictors of breast self-examination. In the health belief model questions most agree with the phrase "Early detection leads less surgical intervention and best healing" and the most disagree with the phrase "I do not check because the leave the condition on God". In Harbi, et al. study the most agree with "BC dangerous to my health" and disagree with "do not check because it is discomfort" [7]. Since breast screening is a high-performance method for young people as part of screening programs, and given the fact that in countries such as Iran, breast cancer is a growing problem, training how to do breast self-examination and risk factors for breast cancer can be a program to prevent breast cancer [24]. Our results showed that $31.6 \%$ had a positive family history of breast cancer that in the study of Yadgarfer, et al. this percentage was $11.6 \%$ [28]. In the present study, there was no significant relationship between age of people with sensitivity, severity, barriers and perceived benefits. This conclusion is not consistent with the study carried out by Naghibi, et al. [29]. It is usually expected that people with a higher age will feel at risk and attempt to self-exam, but in our subjects, we did not change with age. Also, in the study of Fuladi and colleagues, there was a direct correlation between the age of people with perceived sensitivity and perceived barriers [30]. In the present study, there was a significant relationship between age and general knowledge. That is, in our subjects, people with increasing of age are trying and tend to improve their awareness in 
this field, but this awareness may not lead to doing BSE. Venka study in India revealed a direct relation between age and awareness [24]. The study in Nigeria indicated that age to 49 and awareness is a direct relation [31]. In this study there is no relation between number of children and awareness this result confirms Ghorbani's study in Tabriz [25]. There is no relation between occupation and other factors but between having a job and general benefits in Fuladis study is a direct relation [30]. In our study, between occupation and general awareness was no relation which was not compatible the study of Ghorbni in Tabriz [25]. In our study, between marital status, breast-feeding, education and all domains of HBM was no significant correlation. Therefore, in our sample only increase the level of education affects the increase in awareness and does not have a significant relationship with the adoption of health behaviors.In study of Abolfotouh in 2015 which was performed on 225 Saudi women results indicate direct relation between obstacles and benefits with educational level [22]. In our study there is a significant relation between educational level and general awareness but between awareness with marital status and breast feeding was no relation. Tavakolian in study revealed there is a direct relation between educational level and awareness of screening methods [32]. It has also been shown that low level of education directly has a negative attitude toward breast self-examination [33]. The current study showed that there was a significant relationship between perceived family history and perceived sensitivity and perceived severity. Certainly, if one of the family members has breast cancer around people because of the fear of getting cancer, have a greater understanding of the severity and severity of the infection, and the likelihood of doing BSE was increases. This finding is consistent with the results of Nurcan, et al. [8]. Also, the results of a study in Saudi Arabia indicated a positive family history with perceived barriers and benefits [34]. There was a significant relationship between knowledge and positive family history in the current study that is similar to the result of the study by the victim and colleagues [25]. Having a positive family history in one family will definitely increase the knowledge of those around this individual. There was not a significant relationship between the previous history of breast problems and referral to the health belief model. However, there was a significant relationship between previous history of breast problems and referral to physicians with a general knowledge level which is similar to the results of Al-Harbi, et al. [7]. Our study found that there was a meaningful relationship between BSE with perceived benefits and barriers which is in line with other studies in this area [1,7,34,35]. Among our subjects, with increasing awareness of the barriers and benefits of adopting preventive behaviors for breast cancer, they can better decide on action to BSE. In the study of Diderlo, et al. there was a clear relationship between breast self-examination and perceived benefits however, their results indicated that the perceived barriers were not significantly related to the level of breast self-examination [5]. There was no significant relationship between breast self-examination and perceived susceptibility in Parsa, et al. [7,36]. Which contradicts the research results of Gunzales, et al. [34]. In the present study, a meaningful relationship was found between general knowledge and breast self-examination. In other studies, the main reasons for not conducting breast self-examination were lack of awareness $[2,5,11]$. In another study in Nigeria, 78\% did not have a deep awareness of breast self-examination [37]. In the present study, education level was a significant predictor of BSE performance. Certainly, with increasing levels of education, people's understanding of the disease is more and more likelihood action to BSE. In the other study, after adjustment for other potential confounders, education level was not a significant predictor of BSE performance [22]. This was in agreement with previous studies [38] however it was not in agreement with the results of other studies that emphasized the relationship between the women's educational status and BSE performance [3840]. This study, similar to other research studies, has a number of limitations. First, this research is a cross-sectional study that can only determine the relationship between variables and cannot examine the relationship between cause and effect among variables. Second, the results of this study can be generalized to only similar examples and not beyond. In addition, Contributors may underestimated or overestimated their BSE behavior, which in turn might have an impact on the findings of the study.

\section{Conclusion}

In generally, women had poor knowledge on breast cancer. People's knowledge cannot always protect them from diseases and other health problems. Knowledge is a necessary condition; however, it is not sufficient. In addition to knowledge, individuals' beliefs towards health issues and their preventive behaviors play the main role in facilitating or impeding health promoting behaviors [41]. Although most people agreed that self-examination would result in early diagnosis and detection of the disease, only half of the subjects had BSE. In fact, most of the barriers to doing it were reported without having a positive family history. It is recommended that health personnel consider the high predictive variables when designing educational interventions for breast cancer and screening tests. Therefore, it is important factors such as holding training classes on how to do it and emphasizing the importance and importance of doing this self-exam and pointing to the fact that even in the absence of a positive family history, there is the possibility of getting the disease.

\section{Acknowledgement}

The Social Medicine Department of Islamic Azad University of Medical Sciences of Tehran conducted this 
study. The author thanks medical interns of the social medicine rotation.

\section{References}

1. Abu Sharour L, Al-Ghabeesh S, Suleiman K, Salameh AB, Jacoob S, et al. (2017) Predictors of breast self-examination performance among Jordanian university female students. Eur J Cancer Care (Engl) 26.

2. Agbonifoh JA (2016) Breast self examination practice among female students of Tertiary Institutions. Journal of Education and Practice 7: 11-18.

3. Masoudiyekta L, Rezaei-Bayatiyani H, Dashtbozorgi B, Gheibizadeh M, Malehi AS, et al. (2018) Effect of education based on health belief model on the behavior of breast cancer screening in women. Asia Pac J Oncol Nurs 5: 114-120.

4. Ahmadian M, Carmack S, Samah AA, Kreps G, Saidu MB (2016) Psychosocial predictors of breast self-examination among female students in Malaysia: A study to assess the roles of body image, self-efficacy and perceived barriers. Asian Pac J Cancer Prev 17: 1277-1284.

5. Didarloo A, Nabilou B, Khalkhali HR (2017) Psychosocial predictors of breast self-examination behavior among female students: An application of the health belief model using logistic regression. BMC Public Health 17: 861.

6. Sama C-B, Dzekem B, Kehbila J, Ekabe CJ, Vofo B, et al. (2017) Awareness of breast cancer and breast self-examination among female undergraduate students in a higher teachers training college in Cameroon. Pan Afr Med J 28: 91.

7. Al-Harbi MF, Al-Haji K, Moawed SAA, Hawsawi A (2017) Using health belief model to probe female adolescent perception about breast cancer in Riyadh city. American Journal of Nursing Science 6: 358-365.

8. Kırca N, Tuzcu A, Gözüm S (2018) Breast cancer screening behaviors of first degree relatives of women receiving breast cancer treatment and the affecting factors. Eur $\mathrm{J}$ Breast Health 14: 23-28.

9. Ewaid SH, Shanjar AM, Mahdi RH (2018) Knowledge and practice of breast self-examination among sample of women in Shatra/Dhi-Qar/Iraq. Alexandria Journal of Medicine.

10. Hassan MR, Ghazi HF, Mohamed AS, Jasmin SJ (2017) Knowledge and practice of breast self-examination among female non-medical students in universiti Kebangasaan Malaysia (UKM) in Bangi. Malaysian Journal of Public Health Medicine 17: 51-58.

11. Birhane K, Alemayehu M, Anawte B, Gebremariyam G, Daniel R, et al. (2017) Practices of breast self-examination and associated factors among female Debre Berhan University students. International Journal of Breast Cancer 2017.

12. Wu TY, West B, Chen YW, Hergert C (2006) Health beliefs and practices related to breast cancer screening in Filipino, Chinese and Asian-Indian women. Cancer Detect Prev 30: 58-66.

13. Becker MH (1974) The health belief model and personal health behavior. Health Education Monographs 2: 324-473.

14. Rosenstock IM (1990) The health belief model: Explaining health behavior through expectancies.

15. Skinner CS, Tiro J, Champion VL (2015) The health belief model. Health behavior: Theory, research, and practice. $\left(5^{\text {th }}\right.$ edn), San Francisco (US): Jossey-Bass, 75-94.

16. Secginli S, Nahcivan N (2006) Breast self examination remains an important component of breast health: $A$ re- sponse to Tarrant (2006) International Journal of Nursing Studies 43: 521-523.

17. McCance KL, Mooney KH, Smith KR, Field R (1990) Validity and reliability of a breast cancer knowledge test. Am J Prev Med 6: 93-98.

18. Stager JL (1993) The comprehensive breast cancer knowledge test: Validity and reliability. J Adv Nurs 18: 1133-1140.

19. Didarloo A (2014) Studying the knowledge, concern and behavior of female female students for breast cancer in Urmia University of Medical Sciences. Journal of Urmia Nursing and Midwifery Faculty 14: 201-212.

20. Jirojwong S, Manderson L (2001) Beliefs and behaviors about Pap and breast self-examination among Thai immigrant women in Brisbane, Australia. Women Health 33: 47-66.

21. Eslami M, Heidarnia A, Heidarzadeh A, Shokravi F, Motlag ME (2011) Designed to determine the effect of questionnaire validity and reliability of health belief model in two ways users of family planning pills and condoms. Urmia Medical Journal 21: 382-390.

22. Abolfotouh MA, BaniMustafa AA, Mahfouz AA, Al-Assiri $\mathrm{MH}$, Al-Juhani AF, et al. (2015) Using the health belief model to predict breast self examination among Saudi women. BMC Public Health 15: 1163.

23. Baena-Cañada J, Rosado-Varela P, Cortés-Carmona C, Estalella-Mendoza S, Ramírez-Daffós P, et al. (2014) 1364P Spanish women's perceptions of mammography screening. Annals of Oncology 25.

24. Veena K, Kollipaka R, Rekha R (2017) The Knowledge and attitude of breast self examination and mammography among rural women. International Journal of Reproduction, Contraception, Obstetrics and Gynecology 4: 1511-1516.

25. Ghorbani M (2009) Comparison Knowledge, attitude and practice of Barest self Examination. Iranian Journal of Breast Disease 2: 36-42.

26. Jumah JAB (2013) Knowledge \& practice of Saudi women about the prevention of breast cancer. International Journal of Applied 3: 8-13.

27. Grunfeld EA, Ramirez AJ, Hunter MS, Richards MA (2002) Women's knowledge and beliefs regarding breast cancer. Br J Cancer 86: 1373-1378.

28. Yadegarfar Gh, Salami F, Mostajeran M, Ansari R, Rejali M, et al. (2018) Factors engaged with women performance in doing regular breast self-examination or referring to health centers for examination and mammography. The Horizon of Medical Sciences 24: 53-60.

29. Naghibi SA, Daryani S, Shojaizadeh D, Montazeri A (2016) Knowledge, attitude, and practice on breast cancer screening methods among women in the North of Iran. International Journal of Humanities and Cultural Studies 2550-2560.

30. Fouladi N, Pourfarzi F, Mazaheri E, Asl HA, Rezaie M, et al. (2013) Beliefs and behaviors of breast cancer screening in women referring to health care centers in northwest Iran according to the champion health belief model scale. Asian Pac J Cancer Prev 14: 6857-6862.

31. Oladimeji KE, Tsoka-Gwegweni JM, Igbodekwe FC, Twomey M, Akolo C, et al. (2015) Knowledge and beliefs of breast self-examination and breast cancer among market women in Ibadan, South West, Nigeria. PLoS One 10: e0140904.

32. Tavakolian L, Boniadi F, Malekzadeh E (2015) The investigation of factors associated with breast cancer screening among Kazeroon women aged $20-65$ in 2013. Nurs J Vulnerable 1: 17-31. 
33. Gan YX, Lao CK, Chan A (2018) Breast cancer screening behavior, attitude, barriers among middle-aged Chinese women in Macao, China. J Public Health (Oxf).

34. Gonzales A, Alzaatreh M, Mari M, A Saleh A, Alloubani A (2018) Beliefs and behavior of Saudi Women in the University of Tabuk toward breast self examination practice. Asian Pac J Cancer Prev 19: 121-126.

35. Sahraei A, Norouzi A, Tahmasebi R (2013) Predictors of breast self-examination behavior based on health belief model and health control axis in women aged 20 to 50 . Hayat 19: 27-39.

36. Parsa P, Kandiah M (2005) Breast cancer knowledge, perception and breast self-examination practices among Iranian women. Int Med J 4: 17-24.

37. Obaji N, Elom H, Agwu U, Nwigwe C, Ezeonu P, et al. (2013) Awareness and practice of breast self examination among market women in Abakaliki, South East Nigeria. Ann Med Health Sci Res 3: 7-12.

38. Agboola AOJ, Deji-Agboola AM , Oritogun KS, Musa AA, Oyebadejo TY, et al. (2009) Knowledge, attitude and practice of breast self examination in female health Work-ers in Olabisi Onabanjo University Teaching Hospital, Sagamu, Nigeria.

39. Petro-Nustus W, Mikhail BI (2002) Factors associated with breast self-examination among jordanian women. Public Health Nurs 19: 263-271.

40. Karayurt O, Dramal A (2007) Adaptation of champion's health belief model scale for Turkish women and evaluation of the selected variables associated with breast self-examination. Cancer Nurs 30: 69-77.

41. Moodi M, Mood MB, Sharifirad GR, Shahnazi H, Sharifzadeh $G$ (2011) Evaluation of breast self-examination program using health belief Model in female students. J Res Med Sci 16: 316-322. 